\title{
Systemin Peptide Induces Anti-herbivore Defense System by Jasmonic Acid Biosynthesis in Plant
}

\author{
Vijay Pandurang Kapale ${ }^{1 *}$, Chenesh Patel ${ }^{2}$ and Kishor Prabhakar Panzade ${ }^{3}$
}

${ }^{1}$ Department of Biochemistry, ${ }^{2}$ Department of Entomology, ICAR- G. B. Pant University of Agriculture and Technology, Pantnagar, India

${ }^{3}$ ICAR-Indian Agriculture Research Institute, New Delhi, India

*Corresponding author

\section{A B S T R A C T}

\section{Keywords}

Systemin peptide, Jasmonic acid, Biosynthesis, Anti-herbivore defense system

\section{Article Info}

Accepted:

05 June 2020

Available Online:

10 July 2020
Insect attack-wound in plant cells stimulate huge number of signal molecules to induce and activate defense system. Among these one of the intracellular signal molecules are small peptide systemin (18AAs long) produced by proteolytic cleavage in wounded cells from prosystemin (200As) precursor protein. Systemin then bind to its SR-160 (Systemin Cell Surface Receptor) protein (160 kD) and activate phospholipase A2 (PLA-2) that releases linolenic acid, which is initial precursor for JA biosynthesis. Consequently JA induces expressions of many genes encoding defense related proteins and biologically functional molecules such as protease inhibitors, secondary metabolite etc. However, very less is known about how some peptides like systemin actually induces JA biosynthesis in wounded and healthy leaves. Like biotic stress, systemin may also be involved in abiotic stress tolerance.

\section{Introduction}

In plants cell-to-cell communication is central in order to regulate optimum growth and development. Almost all plant suffers through some biotic and/or abiotic stress. Of these insects are the one of the most danger threats to the survival of plants, since they are abundance in nature with huge diversity. Insects make attack and up take food nutrients from plants. Many genes, implicated in herbivore avoidance, defense system, wound response and healing processes, are expressed in respond to herbivorous insect attack and one of the important aspects of induced defense response in plants are occurrence of 
both local and systemic response. It's from many years ago, several molecules contributing in receiving and initiating the systemic defense system in response to wound signal in plant have been discovered (Walling, 2000). systemin signal peptide (18 AAs long) which derived from its precursor called Prosystemin. The systemin are implicated not only in the direct but also in the indirect mechanism of regulation of the plant's protective response to external stimuli by biotic stress(es). The SR-160 (Systemin Cell Surface Receptor) protein (160 kD) acting as receptor for specifically binding to systemin, After binding of systemin to receptor, the membrane bound phospholipase is activated, which releases linolenic acid from the phospholipids of the cell membrane. Linolenic acid is a precursor of biosynthesis of jasmonic acid which is one of the main "protective" plant hormones (Li et al., 2003). In this review article we mainly focused on the recent progress and mechanism of systemin induce defense system against herbivores in plant.

\section{Systemin: The first plant peptide hormone}

In plant, even a small injury to a single leaf by insects or wounding increases the local as well as systemic accumulation of various toxic protease inhibitors (PIs) protein within 2 h (Howe et al., 2000; Ryan, 2000). These PIs inhibit guts located digestive enzymes of insects. Green and Ryan (1972) study how wound-inducible PIs produced in plant and discovered that some unknown specific signal molecule produced at and traveled from wounded site to other healthy leaves, where it induces the expression of PIs encoding genes. Further study by Ryan and his colleagues discovered systemic wound signaling as elicitors for PIs expression in plant. Moreover a compound called systemin, identified from wounded tomato leaf extracts, which translocated via the phloem to distal undamaged leaves and induce PI expression in wounded and non wounded leaf (Pearce $e t$ al., 1991). These indicate that systemin might be act systematically for activation of genes encoding defense related functional molecules in plants (McGurl et al., 1992). In the healthy targeted cells by insects, the interaction of systemin with its SR-160 (Systemin Cell Surface Receptor) receptor protein (160 kD) activate biosynthesis of JA by octadecanoid pathway. Consequently JA induces genes encoding defense molecules.

\section{The octadecanoid pathway for JA biosynthesis}

Systemin released from insect infected and/or wounding tissues and activate defense system by increasing the accumulation of several endogenous compounds belong to the jasmonate family including JA precursor 12OPDA (12-oxo-phytodienoic acid), JA acid and it functional derivative (Farmer and Ryan, 1992; Doares et al., 1995; Li et al., 2002). In wounded tomato leaves, systemin activates a membrane localized phospholipase A-2 (PLA-2) that hydrolyzes the fatty acid from sn-2 position of phospholipids and releases linolenic acid (LA) (Narvaez-Vasquez et al., 1999). Released linolenic acid acts as precursor for biosynthesis of jasmonic acid by octadecanoid pathway. The chloroplasts localized lipoxygenase, allene oxide cyclase and allene oxide synthase are key enzymes of octadecanoid pathway by which OPDA biosynthesis take place (Feussner and Wasternack, 2002; Turner et al., 2002). OPDA acts as metabolic precursor for jasmonic acid. That indicating the initial conversion of LA to OPDA takes place in chloroplast. Then OPDA transported to the peroxisome from the chloroplast. In peroxisome OPDA converts in to 3-oxo-2-(2' (Z)-pentenyl)-cyclopentane-1-octanoic acid (OPC-8:0) by 12-oxo-phytodienoic acid reductase (OPR). Furthermore OPC-8:0 
undergo in to three cycles of $\beta$-oxidation and convert in to JA. Not only JA but also its derivatives such as JA-Ile, MeJA etc induces defense system in plant. The recent findings concluded that a specific JA derivatives with isoleucine forms active jasmonoyl-isoleucine (JA-Ile), which is an only derivative that binds to the COI1-JAZ receptor and consequently induces ubiquitination and subsequently lead to degradation of JAZ (jasmonate ZIM-domain) repressor proteins (Suza and Staswick, 2008; Yan et al., 2009; Sheard et al., 2010).

\section{The core JA signaling module}

The key factors involved in JA signaling are JA responsive transcriptional factor AtMYC2 (Xu et al., 2002) and JAZs receptor (Thines et al., 2007). JAZ proteins in response to JA-Ile, shows the molecular connection between COI1 and AtMYC2 transcription factor. The recent study indicate that COI1 and JAZ forms complex and which acts as receptor for JA-Ile since COI1 contains an active site that recognizes and bind to jasmonoyl-Lisoleucine JA-Ile (3R, 7S) and a degron sequence, which is required for binding of JA-Ile with high affinity to COI1, present on JAZ repressor protein. Once the active JA-Ile binds to COI-1-JAZ complex receptor, induces interaction between $\mathrm{JAZ}$ repressor proteins and the f-box $\mathrm{SCF}^{\mathrm{COI} 1}$ resulting proteolytic degradation of JAZ protein by $26 \mathrm{~S}$ proteasome. Hence JA-Ile relives repression on transcriptional factor AtMYC2 (thines et al., 2007).

\section{Systemin Increases JA Biosynthesis}

Recent study in tomato mutants indicate that from wounded tissue systemin is produced which in turn increases JA biosynthesis. Tomato mutant for spr2 called as suppressor of prosystemin-mediated responses 2 clearly showed decrease in JA biosynthesis as well as in the expression of defensive PI genes in distal leaves. Moreover it was confirmed that systemin activate phospholipase A-2 which hydrolyzes the fatty acid from sn-2 position of phospholipids and releases linolenic acid (LA). These results provide evidence for systemin via JA biosynthesis induces the activation of anti-herbivore defense system along with PI expression in distal leaves of plant (Li et al., 2003).

Conclusion of the study is as follows:

Well clearly known JA as a wound hormone in almost all plant species. On the other hand, how the JA induces its local and systemic effects is still not completely understood. Further isolation and characterization of various wound signals including peptides and studying their mechanisms in defense system is centrally important. At wounding / herbivore attacked site, herbivore may releases some proteolytic enzymes which process precursor protein to produce active peptides but this phenomena is still not confirmed by experimental study. Systemin induces defense gene expression via JA biosynthesis provides an ideal system to clearly understood the signal transduction events in plants to herbivore attack.

\section{References}

Doares, S.H., Syrovets, T., Weiler, E.W., and Ryan, C.A. (1995). Oligogalacturonides and chitosan activate plant defensive genes through the octadecanoid pathway. Proc. Natl Acad. Sci. U S A, 92: 40954098.

Farmer, E.E., and Ryan, C.A. (1992). Octadecanoid precursors of jasmonic acid activate the synthesis of wound-inducible proteinase inhibitors. Plant Cell, 4:129134.

Feussner, I., and Wasternack, C. (2002). The lipoxygenase pathway. Annu. Rev. Plant Biol, 53: 275-297.

Green, T.R., and Ryan, C.A. (1972). Wound- 
induced proteinase inhibitor in plant leaves: a possible defense mechanism against insects. Science, 175: 776-777.

Howe, G.A., Lee, G.I., Itoh, A., Li, L., and DeRocher, A.E. (2000). Cytochrome P450 dependent metabolism of oxylipins in tomato: cloning and expression of allene oxide synthase and fatty acid hydroperoxide lyase. Plant Physiol., 123: 711-724.

Li, C., Liu, G., Xu, C., Lee, G.I., Bauer, P., Ling, H.Q., Ganal, M.W., and Howe, G.A. (2003). The tomato suppressor of prosystemin-mediated responses 2 gene encodes a fatty acid desaturase required for the biosynthesis of jasmonic acid and the production of a systemic wound signal for defense gene expression. Plant Cell, 15: 1646-1661.

Li, L., Li, C., Lee, G.I., and Howe, G.A. (2002). Distinct roles for jasmonate synthesis and action in the systemic wound response of tomato. Proc. Natl Acad. Sci. U S A, 99: 6416-6421.

McGurl, B., Pearce, G., Orozco-Cardenas, M., and Ryan, C.A. (1992). Structure, expression, and antisense inhibition of the systemin precursor gene. Science, 255: 1570-1573

Narvaez-Vasquez, J., Florin-Christensen, J., and Ryan, C.A. (1999). Positional specificity of a phospholipase A activity induced by wounding, systemin, and oligosaccharide elicitors in tomato leaves. Plant Cell, 11: 2249-2260.

Pearce, G., Strydom, D., Johnson, S., and Ryan, C.A. (1991). A polypeptide from tomato leaves induces wound-inducible proteinase inhibitor proteins. Science, 253: 895-897.
Ryan, C.A. (2000). The systemin signaling pathway: differential activation of plant defensive genes. Biochim. Biophys. Acta., 1477: 112-121.

Sheard, L. B., Tan, X., Mao, H., Withers, J., Ben-Nissan, G., Hinds, T. R., Kobayashi, Y., Hsu, F. F., Sharon, M., Browse, J., He, S. Y., Rizo, J., Howe, G. A., \& Zheng, N. (2010). Jasmonate perception by inositolphosphate potentiated COI1-JAZ co receptor. Nature, $468: 400-405$.

Suza, W.P., and Staswick, P.E. (2008). The role of JAR1 in JasmonoylL: -isoleucine production during Arabidopsis wound response. Planta, 227: 1221-1232.

Thines, B., Katsir, L., Melotto, M., Niu, Y., Mandaokar, A., Liu, G., Nomura, K., He, S.Y., Howe, G.A., and Browse, J. (2007). JAZ repressor proteins are targets of the $\mathrm{SCF}^{\mathrm{COI1}}$ complex during jasmonate signalling. Nature, 448: 661-665.

Turner, J.G., Ellis, C., and Devoto, A. (2002). The jasmonate signal pathway. Plant Cell. 14 : $153-$ S164

Walling, L.L. (2000). The myriad plant responses to herbivores. J. Plant Growth Regul., 19: 195-216.

Xu, L., Liu, F., Lechner, E., Genschik, P., Crosby, W.L., Ma, H., Peng, W., Huang, D., and Xie, D. (2002). The SCFCOI1 ubiquitinligase complexes are required for jasmonate response in Arabidopsis. Plant Cell, 14: 1919-1935.

Yan, J., Zhang, C., Gu, M., Bai, Z., Zhang, W., Qi, T., Cheng, Z., Peng, W., Luo, H., Nan, F., Wang, Z., and Xie, D. (2009). The Arabidopsis Coronatine Insensitive1 protein is a jasmonate receptor. The Plant cell, 21: 2220-2236.

\section{How to cite this article:}

Vijay Pandurang Kapale, Chenesh Patel and Kishor Prabhakar Panzade. 2020. Systemin Peptide Induces Anti-herbivore Defense System by Jasmonic Acid Biosynthesis in Plant. Int.J.Curr.Microbiol.App.Sci. 9(07): xx-xx. doi: https://doi.org/10.20546/ijcmas.2020.907.474 